\title{
Pesquisas Pré-históricas no Mato Grosso
}

\author{
Águeda Vilhena Vialou*
}

Pré-História e seus Paleoambientes na Bacia do Paraná e Mato Grosso é um programa científico (MNHN - França e MAE/USP- Brasil) de 20 anos de pesquisas pluridisciplinares reunindo ciências naturais e ciências humanas centrado em duas regiões: - Cidade de Pedra, Rondonópolis, nas formações areníticas ruiniformes há 130 abrigos com representações rupestres, alguns deles com ocupações ceramistas do Holoceno Recente com importante indústria lítica; - e abrigo rupestre Santa Elina, Jangada, situado em um dobramento calcário, contém uma rica sequiência de ocupações durante o Holoceno Médio com excepcionais vestígios vegetais. Esse sítio preservou restos ósseos de Glossotherium, megafauna fóssil associada à indústria lítica em dois níveis arqueológicos, tanto no Holocenio Inicial, há 10000 anos como há 25000 anos no Pleistoceno final caso ainda único no Brasil.

Palavras-chave: Cidade de Pedra. Santa Elina. Arte rupestre.

Prehistory and its Paleoenvironement in the Parana river basin and Mato Grosso is a 20 years long scientific program between France (MNHN) and Brazil (MAE USP). This program combined both natural science and social studies
ב a pedra que resiste ao tempo. Ela está presente em todos as épocas e em todas as culturas! Tomemos como exemplo o biface de St Acheul - 500 mil anos, uma ponta de projétil da cultura Clóvis, 11000 anos, decoração nas fachadas das casas, uma escultura de Aleijadinho nas cidades históricas-barrocas de Minas Gerais, de meados do séc XVIII ou mesmo uma enorme e pesada pedra para esmagar, triturar ou afiar ainda do séc XX. Verifica-se que na maioria dos casos ela não existe por ela mesma, ela está associada a outros vestígios e é significativa a outras atividades. Uma lâmina de machado poli$d a$, por exemplo, apesar de ser imponente, não existe por si própria, mas em relação ao meio onde vai interagir. Assim o testemunho da pedra como utensílio é um testemunho parcial de uma ação.

\footnotetext{
* Professora Dr ${ }^{\mathrm{a}}$. do Muséum National d'Histoire Naturelle (Paris - França). Professora vistante do Museu de Arqueologia e Etnologia da USP (São Paulo - Brasil). Professora convidada da PUCRS Porto Alegre - avialou@mnhn.fr
} 
focusing in two regions. Cidade de Pedra, Rondonópolis, is a sandstone formation that encloses 130 shelters with rock art, some of them having ceramic-producing population from Later Holocene and important lithic industry. The rock painting shelter Santa Elina, Jangada, is located in a limestone folding which hold several sequences of occupations from Middle Holocene together with exceptional botanical remains. This particular site preserved bone remains of a Glossotherium, a megafauna fossil linked with lithic industry in two distinct archeological periods the Early Holocene, around 10000 years ago, and the Late Pleistocene around 25000 years ago, which is currently the only case in Brazil.

Keywords: Cidade de Pedra. Santa Elina. Rock Art.

Mesmo assim é a pedra que atravessa as épocas, a evolução humana com suas cronologias e ela é o único testemunho que pode e que faz a história/estória da Pré-História. No Brasil, como na América em geral, há um encurtamento dessse passado devido a descobertas referentes somente a partir do Homem Moderno da Pré-História, Homo Sapiens Sapiens, e até hoje todos os achados de vestígios humanos não ultrapassam 10000 anos. O que é muito recente em relação aos 2,5 milhões de anos da presença do Homem em outras partes do mundo, na Africa, na Ásia, e mais de 1 milhão de anos na Europa (Dmanissi, 1.5 ka e Atapuerca, $1.2 \mathrm{ka})$.

No final dos anos 70 e início dos anos 1980, boa parte do Brasil já tinha suas referências a pesquisas de campo e um quadro cronológico de ocupações préhistóricas se estabeleceu entre ocupações ceramistas e as líticas, ou seja anteriores à cerâmica. Diferentes tipos de culturas foram discriminados, as litorâneas, sambaquianas, as "evoluídas culturas amazônicas" pelas suas cerâmicas variadas e bem elaboradas, as "produtoras de arte" nos abrigos rupestres de várias regiões. Já se podia falar de habitações e de aldeias pré-históricas.

No Estado de Mato Grosso, dessa época englobando MT e MS, poucas pesquisas regulares tinham sido realizadas e referem-se sobretudo a sítios rupestres. Um deles, o abrigo do Sol, pesquisado por Eurico Miller, dava uma antiguidade inesperada para essa região do oeste do Centro-Oeste, limite com o território de Guaporé. Vestígios de até 14000 anos atrás.

Nesses anos pesquisávamos em sítios a céu aberto do Estado de São Paulo, no vale do Paranapanema. Um dia, em dezembro de 1982, um político e fazendeiro paulista, Carlos Alberto Viana Ferraz Egreja, através do vice- 
prefeito de Ipauçu, veio nos contatar para nos infomar que em uma fazenda que ele tinha no Mato Grosso, Francisco Antiqueira, piloto de seu avião particular, havia descoberto um abrigo com pinturas rupestres. Ele queria que fôssemos lá para autenticar a descoberta. Passamos 5 dias no local à beira do rio Vermelho, ignorando as explorações agrícolas que se faziam no platô e descobrindo uma paisagem de relevo acidentado com uma vegetação exuberante e excepcionalmente preservada. Nessa curta campanha, sondagens feitas ao pé do abrigo com representações rupestres confirmaram presenças humanas contínuas no abrigo até sua base rochosa e foram assim obtidas as primeiras datações do sudeste do Mato Grosso : 4600 e 3600 anos BP, para o abrigo Ferraz Egreja.

\section{Considerando a Pré-História como Ciência da Terra e Ciência Huma-} na, propusemos um Programa pluridisciplinar de pesquisas, reunindo duas instituições com bases sólidas para efetuar as colaborações com nível científico equivalente onde cada ambiente universitário poderia trazer suas contribuições, em função de suas especialidades. Como fiz (AVV) parte do quadro de professor-pesquisador da Universidade de São Paulo, pelo Museu Paulista até 1977, com formação em Ciências Sociais (Antropologia-Sociologia), e meu doutorado pela FFCL da USP em 1980, pude agilizar os contatos universitários, tendo como interlocutor da USP, Museu Paulista, a Prof. Dra Luciana Pallestrini. Do lado francês, Denis Vialou, professor titular do Muséum National d'Histoire Naturelle, Paris, pôde, pela sua instituição e pelo Laboratório de Pré-História, constituir uma equipe.

Assim desde 1983/1984, foi lançado o Programa de Pesquisas : PréHistória e seus Paleoambientes na Bacia do Paraná e no Mato Grosso e foi criado um convênio entre a USP, São Paulo e o MNHN, Paris, juntamente e em acordo com o IPHAN brasileiro. A Fapesp financiou a primeira campanha no Mato Grosso e a partir do 1985 esse programa de pesquisas foi proposto e foi aceito pela comissão consultativa de pesquisas arqueológicas do Ministério de Relações Exteriorers (Ministère des Affaires Etrangères França) que desde então financia as campanhas de pesquisas cada ano e até hoje. O Programa conta com o apoio do MAE-USP e das propriedades particulares onde ocorrem as pesquisas, Sociedade Pecuária Tamarineiro e Agropecuária Basso. 
O objetivo dessas pesquisas é de compor um primeiro quadro sobre os povoamentos e as culturas pré-históricas de uma região de localização geográfica estratégica por estar situada no Centro da América do Sul, entre as grandes bacias hidrográficas, a do rio Amazonas, ao norte e ao sul a Bacia Platina, pelos rios Paraguai e Paraná. Foi definido um programa de longa duração, permitindo prospecções e escavações sistemáticas e um estudo exaustivo da arte rupestre por meio de relevés. A partir do início das pesquisas tivemos a oportunidade e a primazia de trabalhar com os primeiríssimos dados colhidos e que se revelaram muito importantes, oferencendo condições para se estabelecer uma grade dos povoamentos pré-históricos de uma região por nós delimitada.

A equipe foi constituída de especialistas em várias disciplinas correspondendo a diversidade do estudo de um paleoambiente ocupado pelo Homem. Recorremos à cerca de 30 especialistas de diferentes universidades do Brasil, da França e também de outros países, Marrocos, Estados Unidos, Portugal. (ver Pré-história do Mato Grosso, volumes 1 e 2 EDUSP, 2005 e 2006).

Nesses 25 anos de pesquisas, muitas novidades de análise foram introduzidas nos sítios mato-grossenses que pesquisávamos, relevés das representações rupestres, relevés dos solos de habitacão, numeração e registro in loco dos vestígios... Naturalmente foram integradas metodologias recentes ainda não utilizadas no Brasil, como métodos de datação por Uranio-tório, por Luminescêcia ótica estimulada..., as análises de sedimentos por micromorfologia, a antracologia, as análises de pigmentos por Raman...

Ao mesmo tempo, avanços técnicos surgiram no decorrer da pesquisa, a utilização da Estação Total, as fotos digitais e que tiveram de ser incorporadas ao sistema anterior de registro do material arqueológico e fotográfico. Nota-se o grande avanço para as prospecções e localizações precisas dos sítios pelo GPS e SIG.

Estratigrafia, solos ocupacionais, organização espacial, distribuição e arranjo dos vestígios em um sítio arqueológico são as orientações estabelecidas a cada uma de nossas etapas de campo. A interligação entre um e outro hábitat de períodos e idades próximas nos leva a refletir sobre o aprovisionamento de matériaprima, as implantações habitacionais e as noções de território, como um espaço frequentado por um mesmo grupo. 
Visíveis, às vezes de longe, as pinturas nas paredes de abrigos rochosos estão quase convidando os pesquisadores a começar umas pesquisas nas proximidades deles com sondagens e eventualmente escavações. De fato, o estudo da "arte" dos abrigos rupestres isolado das informações que se obtem através das escavações sistemáticas torna-se vazio de todo contexto cultural que ela contém. Por essa razão e quando possível foram feitas escavações de grandes dimensões a fim de obter o maior número de informações do espaço ocupado. Assim, consegue-se saber se trata de uma incursão passageira ou de uma instalação mais duradoura e sobretudo se há uma sequência estratigráfica com superposições de ocupações num mesmo espaco habitacional, por exemplo, para o conhecimento de quem elaborou as pinturas, desenhos ou gravuras e em que época.

Duas regiões foram escolhidas para as pesquisas e foram pesquisadas concomintantemente :

- área 1: Cidade de Pedra, próxima a Rondonópolis, e com a finalidade de proteção ecológica e arqueológica tornou-se em 1998 uma RPPN, "Reserva Ecológica Basso”, pertencente à Agropecuária Basso S/A. A área de pesquisa é de 20 por $20 \mathrm{~km}$ e possui mais de 130 abrigos rupestres inventariados, em morros ruiniformes, situados numa formação arenítica da Serra São Jerônimo. Foram sondados e escavados 11 abrigos, Antiqueira, Arco da Coruja, Arqueiros, Cipó, Falha, Ferraz Egreja, Morro Solteiro, Pacífico, Sêlos, Tocaçu dos Morcegos e Vermelhos e 5 sítios a céu aberto, Aldeia Morro Solteiro. Baia 58, Fazendinha, Jatobá, Turbina;

e

- área 2: Santa Elina, abrigo rupestre, situado a 40km NO do município de Jangada, na cadeia montanhosa da Serra das Araras, está localizado num dobramento sinclinal de calcário do Pré-cambriano. A ausência de outros sítios rupestres na região, acrescido da riqueza de vestígios fornecidos pelo abrigo, fez com que a pesquisa tenha sido totalmente dedicada às escavações desse abrigo. 


\section{Area 1-Arte rupestre e hábitat na CIDADE dePEDRA}

Essa região é surpreendente pela riqueza de abrigos rupestres, 130 abrigos até hoje, e provavelmente mais abrigos a serem descobertos na campanha desse ano 2009. O estudo das representações rupestres dessa região revela uma unidade de composição desses desenhos e pinturas. São essencialmente representações de sinais, de figuras geométricas como pontos, barras, círculos, quadrangulares e ovais com preenchimentos lineares..., isolados, agrupados e organizadas de maneira bem variada. A singularidade de alguns desses sinais, fez com que fossem classificados como motivos e cada abrigo, ou conjunto de abrigos possui o seu motivo específico, tal como um "emblema".

Nesse espaço reduzido e de relevo acidentado, com um desnível de 400m, indo do platô ao rio Vermelho, e cortado por quatro micro-bacias, as análises das representações enriquecidas dos resultados das escavações nos abrigos atestam a noção de territórios de ocupação. É possível distinguir áreas geográficas respectivas de povoamento pelas representações que foram confiadas às paredes. As representações rupestres são o testemunho mais representativo da concepção dos laços sociais de uma cultura e que correspondem ao pensamento coeso de um grupo e de seu imaginário. Trata-se de comportamento simbólico.

As pequisas concernentes ao hábitat mostram que houve reocupações em um mesmo local de habitação, implicando superposições e fases distintas de depósitos. Normalmente as escavações nos abrigos da Cidade de Pedra registram passagens sucessivas e que perduraram milênios. Os abrigos Ferraz Egreja,Vermelhos e Antiqueira pertencentes a micro-bacias diferentes e distantes de mais de $6 \mathrm{~km}$ um do outro apresentam vestígios cerâmicos, líticos e de fogueiras a partir de organizações de espaço habitacional ao longo de uma sequência de ocupações ceramistas. Apesar de estarem ocupando os sítios em períodos contemporâneos, entre 1300 e 600 anos BP, suas relações ao hábitat é entre eles bem diferenciada.

- Em Antiqueira a cerâmica, embora seja o vestígio determinante das passagens do homem pré-histórico no abrigo, ela é reduzida e pouco diversificada. O lítico bem raro, mas tem um caráter excepcional: há 6 
lâminas de machado em rocha verde, uma matéria-prima rara, preciosa. Quanto à organização espacial há fogos que são provenientes de fogueiras, entretanto as fogueiras são formadas unicamente pelo conjunto de carvões, dando marcas de incandescência ao solo.

- Nos Abrigos Vermelhos encontram-se estruturas de combustão formadas por pedras, muita indústria lítica, lascamentos in loco, e pouquíssimo material cerâmico.

- Em Ferraz Egreja as estruturas de combustão podem ser formadas por um forro de pedras, como podem ser fogueiras feitas de pequenos galhos e gravetos agrupados. Enormes tições (quase de 1 metro por $30 \mathrm{~cm}$ ) jogados fora da área de combustão ocorrem em alguns solos das ocupações. O abrigo Ferraz Egreja se caracteriza pela indústria lítica com lascamentos in loco, contendo assim toda a variedade da produção do lascamento e sua cadeia operatória: blocos e seixos trazidos ao acampamento/moradia, percutores, núcleos, lascas, fragmentos e estilhas de lascamento e de retoque. São peças de tamanhos milimétricos mas que comprovam o trabalho de acabamento do utensílio no próprio sítio. $\mathrm{O}$ material cerâmico, proporcionalmente muito reduzido em relação ao lítico, é bastante significativo pela sua diversidade e pelos pequenos vasilhames aí presentes.

Essas caracterizações sintetizadas de três abrigos mostram suas diferenças já quanto ao comportamento técnico e possivelmente de subsistência como denotam diferenças no uso do abrigo. Todos encontram-se distantes do eixo principal, o rio Vermelho e de suas fontes de matéria-prima. Relevante é notar também que eles se distinguem totalmente na simbologia das representações rupestres, não só tecnicamente, pela escolha de pigmentos (branco -Antiqueira), como das disposições parietais (em painéis ininterruptos em paredes e teto nos Abrigos Vermelhos) dos temas representados (motivos únicos de Ferraz Egreja).

A localização do abrigo juntamento com sua topografia e sua morfologia condicionam o tipo de presença no sítio. Os abrigos aqui citados têm características também diferentes quanto à própria constituição do abrigo.

- Antiqueira é uma caverna-abrigo, situada ao pé de um maciço rochoso, orientado ao sul, muito bem protegido pela profundidade e configuração 
da caverna e por um talude de depósitos na vertical da alta parede do maciço. Pela obscuridade decorrente dessa localização, é um sítio sombrio e úmido. Não é adequado a instalações duradouras.

- Vermelhos está situado em uma junção de blocos areníticos formando um teto, mas com possibilidade de penetrações de água. Ele é bem vazado e está no mesmo nível que o terreno circundante. Os depósitos contêm muitos blocos. É um sítio quente e atualmente longe de fontes de água em época de seca.

- $\quad$ Ferraz Egreja encontra-se em um pequeno morro isolado. É um sítio que tem a forma de um cogumelo: o teto é uma excelente proteção das intempéries e sua parede, tal uma larga coluna, permite circundá-lo totalmente. A proximidade de um riacho, $15 \mathrm{~m}$, formando cachoeiras, e sua base rochosa que se encontra a menos de $1 \mathrm{~m}$ de profundidade, conferem a esse sítio condições de um excelente abrigo, apesar de ser atualmente, nos níveis mais profundos em escavação, uma área bastante úmida de acordo com a pluviosidade sazonal.

Somadas as informações topográficas da paisagem e tecnológicas das culturas às manifestações simbólicas, obteve-se um quadro possível de frequentação de um território por um mesmo grupo e suas relações com outros grupos vizinhos. Constatou-se também que, pela transmissão de mesmas convenções estilísticas e temáticas em abrigos rupestres localizados próximos, formaram-se "grupos-famílias" com essas mesmas identidades distinguindo-se de agrupamentos e "famílias" de outros sítios.

Outra dimensão a ser considerada é a duração dessas atividades simbólicas. A cronologia é indispensável para dar uma idade, um período de ocupação. Mas a datação não é a única e não é determinante visto as possibilidades de contatos com outros grupos que podem migrar para essa região. As mudanças de comportamentos visíveis de uma cultura poderiam ser explicadas pela diferença brusca nas estruturas de ocupações. Esse tipo de mudança se verifica nos sítios a céu aberto, onde a cerâmica e o lítico polido têm um papel predominante, diferenciando-se das habitações em abrigos.

Notou-se, no entanto, uma persistência na tecnologia do lascamento nos abrigos ao longo de vários séculos e mais de dois milênions, como em Ferraz Egreja. 


\section{O abrigo rupestre de SANTA ELINA}

Em Santa Elina é uma cronologia longa que interessa a pesquisa. Não se refere aos níveis mais recentes do Holoceno, visto que o sítio foi frequentemente ocupado desde 25000 anos até cerca de 2000 anos atrás e, consequentemente, não foram encontrados vestígios cerâmicos.

Mas é no Holoceno Médio, de 2000 a 8000 anos BP, que ocorrem ocupações ininterruptas, presentes na totalidade desse período. Essas ocupações são precedidas de importantes ocupações do Holoceno Inicial entre 9000 e 10000 anos BP, já com características que as diferenciam das ocupações do Holoceno Médio. E enfim, outras ocupações bem mais antigas, as de 25000 anos BP, do fim do Pleistoceno Superior, fecham a sequência arqueológica.

O abrigo habitacional, situado entre duas paredes calcárias inclinadas, oferece uma área de preservação de vestígios que é rara. Os primeiros e mais antigos vestígios presentes em Santa Elina, foram evidenciados a 3 metros de profundidade, correspondem a uma associação dos vestígios líticos - lascamentos e utensílios confeccionados em calcário detrítico e silícia, rochas exógenas ao abrigo - à uma megafauna fóssil, ossos da parte dianteira de Glossotherium Letsommi, trazidos ao abrigo pelo Homem e dispostos em um solo arqueológico. Os vestígios foram encontrados em uma mesma camada formada de sedimento arenoso com blocos calcários. Para a análise cronológica de vestígios provenientes do mesmo nivel e próximos entre êles, foram utilizados tres métodos de datação (AMS, U-TH, OSL) realizalisados em tres laboratórios diferentes (GIF, MNHN, Univ. Washington) e em tres materiais distintos (partículas de carvão, ósseo e grãos de quartzo do sedimento). As idades obtidas foram concordantes, respectivamente, 23000, 27000 e 27000.

Um outro nível arqueológico, também em depósito arenoso, a 2 metros de profundidade do solo atual, preservou testemunhos de ocupação humana pelo material lítico, pelas fogueiras e pelos restos ósseos de glossotério. Novamente, agora em período de passagem Pleistoceno-Holoceno, 10000 a 9000 anos BP, o Homem pré-histórico nao só foi contemporâneo, mas conviveu com a fauna extinta, trazida ao abrigo, tal como no período de 25000 anos atrás.

Entre 8000 e 7000 anos BP os sedimentos nesses períodos são ainda arenosos e constituem uma transição sedimentológica aos depósitos finos, 
pulverulentos a partir de 6000 anos atrás, que compõem todo o depósito até os dias de hoje. Vestígios vegetais são abundantes, estacas de madeira (85), trançados, cestaria... frutos diversos. A fauna é diversificada, com a presença predominante de moluscos, gastrópodes queimados e de micro-vertevrados. O lítico é representado principalmente por lascamento em rocha calcária, mas há também utensílios em silex, arenito e quartzo. São notáveis as construções em pedras das estruturas de combustão, regularmente utilizadas por várias ocupações.

Muitos corantes, um milhar de plaquetas de hematita, presentes em todos os níveis holocênicos e também no de 10000 anos BP, são sem dúvida os instrumentos do "artista" e o material que dá o pigmento de cor vermelha amplamente utilizado na parede do abrigo para a confecção das pinturas rupestres. Novecentas representações, sinais, figurações humanas e animais (antas, felino, cervídeos, macacos, aves...) correspondem a diferentes fases de execução. É possível conhecer suas sucessões mas a ausência de datações não permite de dar-lhes uma cronologia.

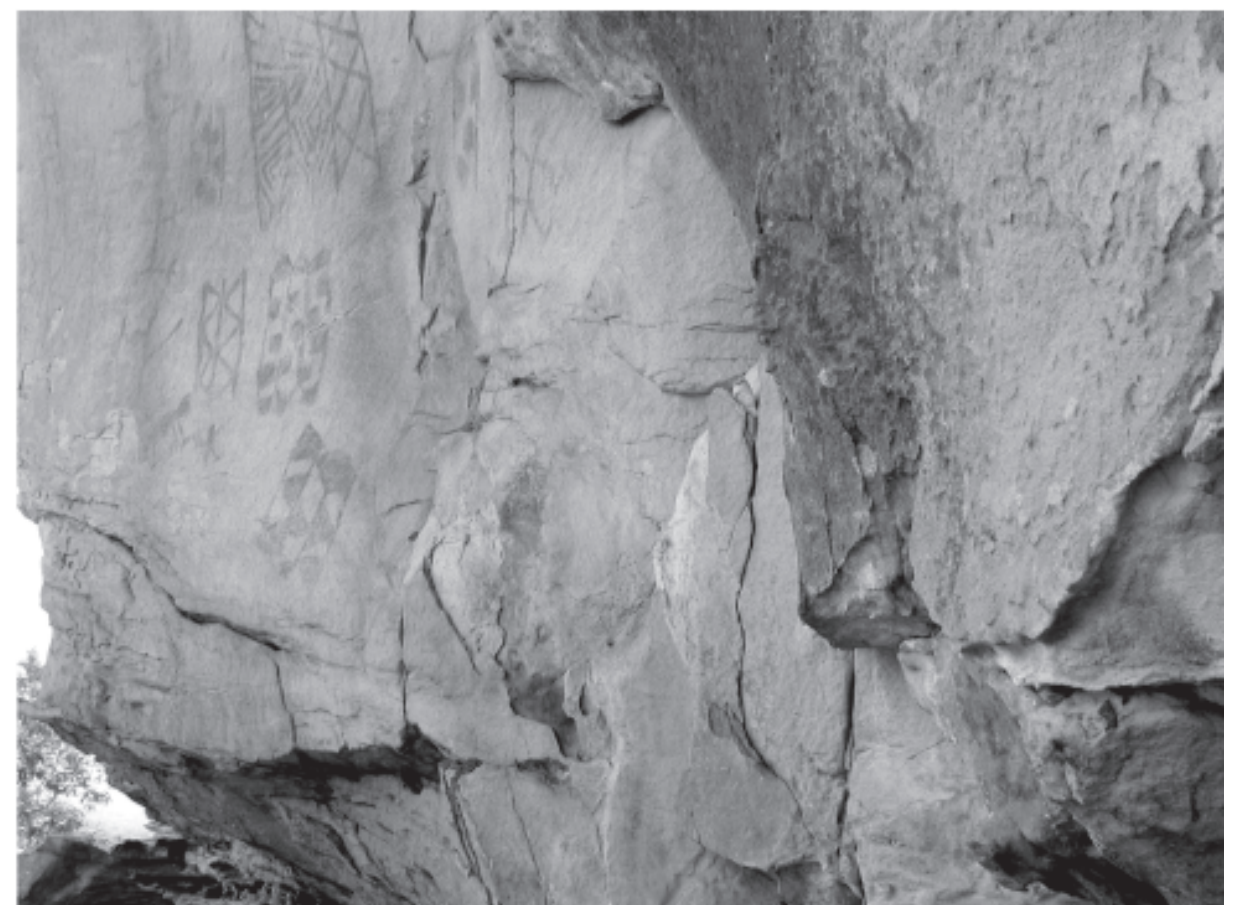

Desenhos rupestres do abrigo Acrobatas na Cidade de Pedra 


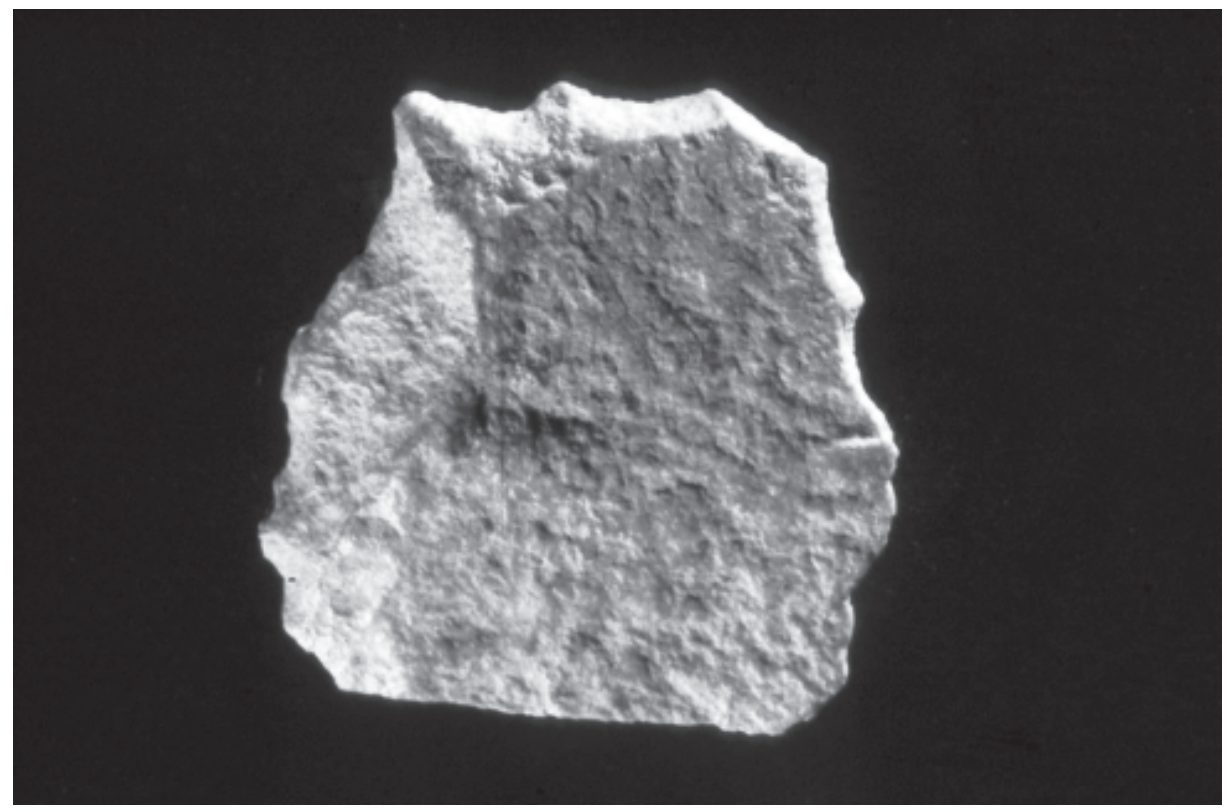

Uma peça lítica denticulada em rocha calcaria do nível de 25000 anos atrás do abrigo de Santa Elina

Como conclusão, verifica-se que o território sudeste mato-grossence foi também amplamento povoado.

Santa Elina tem uma sequência ocupacional longa, excepcional pela antiguidade pleistocênica. É igualmente um sítio único no Brasil pela coexistência do Homem com a Megafauna tanto aos 25000 anos como no início do Holoceno há 10000 anos BP. As ocupações de 8000 a 2000 anos em Santa Elina são as que possuem uma excelente conservação de vestígios. Enquanto que nas regiões do Cerrado do Brasil Central, o Holoceno Médio é em geral mal representado.

Na Cidade de Pedra são as ocupações lito-ceramistas que prevalecem. Pela arte rupestre conhece-se o mundo simbólico dessas populações e podemos estabelecer seus territórios e contatos.

Os homens pré-históricos aí se instalaram, conviveram com outros grupos e se mantiveram nos abrigos locais que lhes pareciam prazeirosos, e não como área de passagem, como indicam as estabilidades e persistências de ocupações nesses últimos 10000 anos. 


\section{obras, filmes, artigos e trabalhos universitários da equipe de pesquisas do Mato Grosso:}

A obra geral Pré-história do Mato Grosso, vol 1e 2, reúne 31 autores e 30 artigos:

VIALOU, A.Vilhena (org.). Pré-história do Mato Grosso. vol 1 - Santa Elina. São Paulo: Edusp São, 2005, 256 p.

VIALOU, A.Vilhena, org., 2006. Pré-história do Mato Grosso. vol 2 - Cidade de Pedra. São Paulo: Edusp, 2006, 232 p.

\section{Filmes:}

1. Filmes pedagógicos e cientificos de nível universitário: 1990-1992 - Expedição Vilhena-Vialou. Centro de Produção Culturel e Educativa (CPCE - da Universidade de Brasilia - Delvair Montagner).

1994-1995 - Passado presente. Centro de Produção Culturel e Educativa (CPCE - da Universidade de Brasilia - Delvair Montagner)

2000 - 500 anos do Brasil, Pré-História no Mato Grosso. Réalisation L. Delion, Production TVCultura, São Paulo, durée 25 minutes.

\section{Filmagem para documentário científico:}

2003 - Primeiros Povos do Planalto. réalisé par L. Delion et H. Carvalho, Production SESC-SENAC de Televisão (STV), São Paulo, durée 55 minutes

\section{Artigos científicos:}

1. BENABDELHADI, M. Santa Elina-Estratigrafia, in Simpósio Mato Grosso : Pesquisas Pluridisciplinares em Pré-História do XIII Congresso Internacional da Sociedade de Arqueologia Brasileira, SAB Campo Grande, 2005, 10 p.

2. BENABDELHADI M. Cidade de Pedra-Ferraz Egreja. Estratigrafia, sedimentologia e micromorfologia, in Simpósio Mato Grosso: Pesquisas 
Pluridisciplinares em Pré-História do XIII Congresso Internacional da Sociedade de Arqueologia Brasileira, SAB Campo Grande, 2005, 7 p.

3. DE BLASIS, P.A.D Abris Vermelhos, Mato Grosso. Premiers résultats. L'Anthropologie, t. 101, nº 3, 1997, p. 546-552, 5 fig.

4. CECCANTINI, G. Os novelos de fibras do abrigo rupestre Santa Elina (Jangada MT) : Anatomia vegetal e paleoetnobotânica. Rev. do Museu de Arqueologia e Etnologia USP, 2003.

5. D'ERRICO, F.\& VILHENA-VIALOU, A. Reduction sequences of colorant material : the rock art site of Santa Elina (Mato Grosso, Brazil) in Rock Art Research, vol $24, \mathrm{n}^{\circ} 2$ november 2007 p.181-190

6. FIGUTI, F.e MONTEIRO, L. C. Aldeias e abrigos : sítios a céu aberto na Fazenda Verde, in XII Congresso internacional da Sociedade de Arqueologia Brasileira, São Paulo, setembro 2003, 7 p.

7. KAMASE, L. Santa Elina (MT) - As estacas de madeira, in Simpósio Mato Grosso : Pesquisas Pluridisciplinares em Pré-História do XIII Congresso international da Sociedade de Arqueologia Brasileira, SAB Campo Grande, $2005,16 \mathrm{p}$.

8. FERREIRA e SILVA, V.C. A exploração do espaço; a relação entre a matéria -prima lítica e sua origem litológica na região da Cidade de Pedra, Bacia do Rio Vermelho (Rondonópolis, MT), in Simpósio Mato Grosso : Pesquisas Pluridisciplinares em Pré-História do XIII Congresso internacional da Sociedade de Arqueologia Brasileira, Campo Grande, 2005, 23 p.

9. GUSSELLA, L.W. e CECCANTINI, G. Identificação de frutos e sementes de sedimentos arqueológicos do abrigo rupestre de Santa Elina (Jangada MT), in Simpósio Mato Grosso : Pesquisas Pluridisciplinares em Pré-História do XIII Congresso internacional da Sociedade de Arqueologia Brasileira, Campo Grande, 2005, 12 p.

10. LIMA, T. Vargas. Sitios rupestres na margem do rio Vermelho - Mato Grosso, in Simpósio Mato Grosso : Pesquisas Pluridisciplinares em Pré-História do XIII Congresso Internacional da Sociedade de Arqueologia Brasileira, Campo Grande, setembro 2005, 4p. 
11. PAILLET, P. Etude préliminaire de nouveaux abris ornés découverts au Brésil : les abrigos Vermelhos (Rondonopolis, Mato Grosso). L'Anthropologie, t. $99, \mathrm{n}^{\circ} 2 / 3,1995, \mathrm{p} .444-458$.

12. PAILlET, P. Art rupestre au Mato Grosso. Les abris Vermelhos. Archeologia, $\mathrm{n}^{\circ} 337$, 1997, p. 50-59, 18 fig., Dijon.

13. PAILLET, P. Diversité de l'art rupestre du Rio Vermelho : le site de Gleba de Cerca (Rondonópolis), Mato Grosso, Brésil. L’Anthropologie, t. 102/2, 1998, p. 177-196.

14. PAILLET, P. Art rupestre au Mato Grosso (région de Rondonopolis, Brésil). Les abris Vermelhos, INORA, 1998, p. 25-31

15. PAILLET, P. Nouvelles découvertes d'art rupestre au Mato Grosso (Cidade de Pedra, Rondonópolis, Brésil) L’Anthropologie 110, 2006, p. 547-579

16. PERIE, J. et VILHENA-VIALOU, A.- Découvertes rupestres et analyses de l'utilisation des paysages par les populations paléoindiennes avec datations dans l'Etat du Mato Grosso au Brésil. C.R. Acad. Sc., Paris, t. 299, série II, n 2, 1984, p. 77-80, 3 fig.

17. SCHEEL-YBERT, R., SOLARI, M.E. Arqueobotânica : integrando indícios sobre meio ambiente, uso de vegetais e agricultura à agricultura in XIIe Congrès international de la Sociedade de Arqueologia Brasileira, São Paulo (Brésil), septembre $2003,2005,7 \mathrm{p}$.

18. VIALOU, D. Un nouveau site rupestre au Mato Grosso, l'abri Ferraz Egreja. Revista do Museu Paulista, nova série, vol. XXXIX, 1983-1984, p. 39-53, 7 fig., USP.

19. VIALOU, D. \& VILHENA-VIALOU, A. avec la coll. de G. DELIBRIAS. Un nouveau site préhistorique brésilien daté : l'abri à peintures et gravures Ferraz Egreja (Mato Grosso). L'Anthropologie, t. 88-1, 1984, p. 125-127, 1 fig.

20. VIALOU, D. \& VILHENA-VIALOU, A. Préhistoire au cœur du Brésil. Archeologia, $\mathrm{n}^{\circ}$ 213, 1985, p. 36-48, 25 fig., Dijon.

21. VIALOU, D. Les peintures pariétales de Santa Elina, Mato Grosso, Brésil. Bull. Soc. Préhist. Fr. Hommage de la S.P.F. à A. Leroi-Gourhan, t. 84, n 10-12, 1987, p. 403-406. 
22. VIALOU, D. Une rencontre des préhistoriens - France-Brésil - Vingt ans de coopération. Coll. Travaux et Mémoires, n 44, I.H.E.A.L., PUG, 1989, p. 89-9.

23. VIALOU, D. \& VILHENA-VIALOU, A. Arts préhistoriques au Brésil. Les Dossiers d'Archéologie, n 169, mai 1992, p. 7-11, Dijon.

24. VIALOU, D. \& VILHENA-VIALOU, A. Arts préhistoriques au Brésil. Les Dossiers d'Archéologie, n 169, mai 1992, p. 7-11, Dijon.

25. VIALOU, D. Préhistoire au cœur du Brésil. C.R. de l'Acad. Sciences d'Outre-Mer, tome LIV, 2-3-4, 1994, p. 158-174.

26. VIALOU, D. \& VILHENA-VIALOU, A. 1996. Art rupestre au Mato Grosso (Brésil). Anthropologie, XXXIV/1-2, 1996, p. 201-213, 9 fig., Brno.

27. VIALOU, D. \& VILHENA-VIALOU, A. Découvertes préhistoriques au Mato Grosso, Brésil. Les Amis du Muséum, n 190, juin. 1997, 17-19.

28. VIALOU, D. Territoires et cultures préhistoriques : fonctions identitaires de l'art rupestre. Sociedades Ibéro-Americano : reflexões e pesquisas recentes. Ed. A. A. Kern et al,. Porto Alegre, EDIPUCRS, 2000, p.381-396.

29. VIALOU, D. Symbolique rupestre et cultures préhistoriques au Brésil, in J. Guilaine (dir.), “Arts et symboles du Néolithique à la Protohistoire » Séminaire du Collège de France, Editions Errance, Paris, 2003, pp 61- 80, 9 fig.

30 VIALOU, D. \& VILHENA VIALOU, A. Art rupestre, habitats et territoires au Brésil, in R. de Balbin Bermann et P. Bueno Ramirez «El arte prehistórico desde los inicios del siglo XXI Primer Symposium Internacional de Arte Prehistorico de Ribadesella ». Associación Cultural Amigos de Ribadesella, 2003, p.481-512, fig

31. VIALOU, D. Santa Elina, MT, Diachronie et synchronie du dispositif pariétal in XII Congresso internacional da Sociedade de Arqueologia Brasileira SAB, São Paulo, set 2003, 2005,10 p.

32. VIALOU, D. \& VILHENA VIALOU, A. L'art rupestre au Brésil in Brésil Indien, les arts des Amérindiens du Brésil, ed. L. D.B. Grupione, Ed de la réunion des musées nationaux, Paris, 2005, p .117-127.

33. VIALOU, D \& VILHENA VIALOU, A. Peuplements, milieux préhistoriques dans le bassin du Paraná, in Archéologies vingt ans de recherches françaises 
dans le monde, Ministère des Affaires Etrangères, Maisonneuve et Larose, ADPF ERC, 2005, p.682-684.

34. VIALOU, D. \& VILHENA VIALOU, A. Modernité Cérébrale - Modernité Comportementale de Homo Sapiens, in Anthropologie XLIII / 2-3, 2005, p. 241-247 Brno.

35. VIALOU, D. L'art préhistorique autour du globe In Figaro Beaux Arts magazine, 2008.

36. VILHENA VIALOU, A. \& VIALOU, D. Fouilles de Brito (São Paulo), art rupestre et fouilles au Mato Grosso, Brésil. Bull. Soc. Préhist. Fr., 82-87, 1985, p. 200.

37. VILHENA VIALOU, A. Art rupestre brésilien. Journal du Groupe Français d'Etude et de Recherche sur les Origines des Représentations Graphiques et Symboliques. (G.R.E.T.O.R.E.P.), juin 1986, n 6, 1986, p. 49-52, Paris.

38. VILHENA VIALOU, A. Santa Elina, fouilles dans un abri rupestre du Mato Grosso, Brésil. Bull. Soc. Préhist. Fr., t. 84, n 10-12, 1987, p. 407-410, 2 fig.

39. VILHENA VIALOU, A. \& VIALOU, D. Art rupestre dans des abris-habitats préhistoriques du Mato Grosso, Brésil. In Ars Praehistorica. Ed. Auja Barcelona, t. VII/VIII, 1988-1989, p. 347-356.

40. VILHENA VIALOU, A. \& VIALOU, D. Abrigo pré-historico Santa Elina, Mato Grosso; habitats e arte rupestre. Revista do Instituto de Pré-História da USP, São Paulo, vol. 8, 1989, p. 34-53.

41. VILHENA VIALOU, A. \& VIALOU, D. Préhistoire du Parana. Les Dossiers d'Archéologie, n 145, févr. 1990, p. 78-81, 4 fig., Dijon.

42. VILHENA VIALOU, A. \& VIALOU, D. Le travail de la pierre. Les Dossiers d'Archéologie, $\mathrm{n}^{\circ}$ 169, mai 1992, 1992, p. 12-15, Dijon.

43. VILHENA VIALOU, A. \& VIALOU, D. Les premiers peuplements préhistoriques du Mato Grosso. Bull. Soc. Préhist. Fr., t. 91, n 4-5, 1994, p. 257 263, 8 fig., bibl.

44. VILHENA VIALOU A. Abrigo rupestre de Santa Elina : ocupações préhistóricas associadas a megafauna. Revista de Historia da Arte e Arqueologia, $\mathrm{n}^{\circ}$ 1, 1994, p. 261-262, FFCH-UNICAMP. 
45. VILHENA VIALOU, A., AUBRY, T., BENABDELHADI, M., CARTELLE, C., FIGUTI, L., FONTUGNE, M., SOLARI, M.E., VIALOU, D. Découverte de Mylodontinae dans un habitat préhistorique daté du Mato Grosso (Brésil). L'abri rupestre de Santa Elina. C.R. Acad. Sc. Paris, t. 320, série IIa, 1995, p. 655-661.

46. VILHENA VIALOU, A. L'art rupestre brésilien. L'archéologue, archéologie nouvelle, $\mathrm{n}^{\circ} 17,1995-1996$, p. 28-32, 6 fig.

47. VILHENA VIALOU, A., BADU, H., D’ERRICO, F., VIALOU, D. Les colorants rouges de l'habitat rupestre de Santa Elina, Mato Grosso (Brésil). Techne, n³ 3, 1996, p. 91-97, 2 ph. couleurs, pl. VIII.

48. VILHENA VIALOU, A. Abri Santa Elina, Mato Grosso, Brésil : habitats préhistoriques avec mégafaune de la fin du Pléistocène. Congrès XIII UISPP, section 17, Forli, 1996.

49. Vilhena Vialou, A. Une pendeloque taillée dans un os de «Glossotherium». Universalis. Encyclopaedia Universalis Paris, 1998, p. 267.

50. VIALOU, D. \& VILHENA-VIALOU, A. Découvertes préhistoriques au Mato Grosso, Brésil. Les Amis du Muséum, n 190, juin, 1997, 17-19.

51. VILHENA VIALOU, A., BLASiS, P.A. de, FIGUTI, L., PAILlET, P., VIALOU D. Art rupestre et habitats préhistoriques au Mato Grosso (Brésil). L'Amérique du sud: des chasseurs-cueilleurs à l'Empire Inca. BAR International series 746. ARAPA, Genève, 1999.

52. VILHENA VIALOU, A. Algunas observações sobre terminologia e tecnologia litica brasileira : problemas atuais. Sociedades Ibéro-Americano : reflexões e pesquisas recentes. Ed. A. A. Kern et al., Porto Alegre, EDIPUCRS, 2000, p.345-361.

53. VILHENA VIALOU, A. Santa Elina rockshelter, Brazil : Evidence of the coexistence of Man and Glossotherium. . In Miotti L., Salemme M., Flegenheimer N. (eds) Where the South Winds Blow. Ancient Evidence of Paleo South Americans. A Peopling of the Americas Publication. Center for the Study of the First Americans, Texas A\&M University, 2003, p.21-28.

54. VILHENA VIALOU, A. Territórios, meios ambientes e culturas pré-históricas na Cidade de Pedras, Mato Grosso, in XII Congresso internacional da Sociedade de Arqueologia Brasileira SAB, São Paulo, set 2003, 2005, 13 p.. 
55. VILHENA VIALOU, A. Santa Elina : suas culturas e sua cronologia, in XIII Congresso internacional da Sociedade de Arqueologia Brasileira, Campo Grande (Brasil), set. 2005, 12 p.

56. VILHENA VIALOU, A. Metodologia de análise para as indústrias líticas do Pleistoceno no Brasil Central. In Das pedras aos homens : tecnologia lítica na arqueologia brasileira. Lucas Bueno e Andrei Isnardis (org.) Sympósio de Tecnologia lítica no Brasil, Belo Horizonte, Argumentum : FAPEMIG ; Brasilia, DF : CAPES, 2007, p.173-192.

57. VILHENA VIALOU, A. \& VIALOU, D. Peuplements préhistoriques au Brésil. Recherches au Mato Grosso In Les Nouvelles de l'Archéologie, Des mers de glaces à la Terre de Feu. Archéologie française en Amérique, Editions de la Maison des Sciences de l'Homme, Editions Errance, n 111-112, avril 2008 p. 17-22

58. WESOLOWSKI, V. Cidade de Pedra, MT : O espaço funerário da Caverna do Cipó, Nota prévia. In XII Congresso international de Sociedade de Arqueologia Brasileira, São Paulo (Brésil), setembro 2003, 2005, 2 p.

59. Wesolowski, V. \& Monteiro, L. C. Cidade de Pedra, MT, Sítio Caverna do Cipó: Cerâmica e funeral. XIII SAB, Campo Grande, 2005.

\section{No prelo:}

VILHENA VIALOU A. \& VIALOU, D. Santa Elina ; a Pleistocene rockshelter in Central Brazil, in SAA 2005 Salt Lake City.

VILHENA VIALOU, A. Tecnologia lítica no planalto brasileiro : persistência ou mudança Congresso Internacional (World Archaeology Congress) IV TAAS Teoria Arqueologica América do Sul, 2007, Catamarca, Argentina. Communicação

\section{Trabalhos universitários:}

BADU, H. Etude de représentations rupestres de l'Abri Alvorada, Mato Grosso. Mémoire de DEA Muséum National d'Histoire Naturelle, 1992, 110 p. 
BARON PARRA, A. M. Etude technologique d'une série lithique du site Brito, São Paulo, Brésil, Mémoire de DEA Muséum National d'Histoire Naturelle, 2002, 47 p, fig. p, fig. CD Rom annexe.

BOUCHARD, M. Evaluation des Capacités de la Microscopie Raman dans la Caractérisation Minéralogique et Physico-chimique de Matériaux Archéologiques : Métaux, Vitraux \& Pigments., thèse de Doctorat, Muséum National d'Histoire Naturelle, Paris. 5 décembre 2001, pp.360 (contient l'analyse de pigments provenant de Santa Elina).

CECCANTINI G. Madeiras Arqueológicas do Abrigo Rupestre Santa Elina M T Tese de Doutorado, área Botânica, Instituto de Biociências, Universidade de São Paulo, 2002, 130 p, fig. CD Rom annexe.

DIAS, Cleonice. Ferraz Egreja TGI UFMT Rondonópolis, 2005.

GUSSELLA L. W. Artefatos arqueológicos confeccionados em fibras vegetais (Jangada M T). Congresso da Sociedade Botânica, 2004.

FERREIRA e SILVA, V. C. A exploração dos recursos litológicos na região da Cidade de Pedra, Rondonópolis - MT. Dissertação de Mestrado, 04/04/06, MAEUSP, 2006.

JUNDI, A. La problématique de l'apport ethnographique pour l'étude de l'art rupestre au Brésil. Mémoire de DEA Muséum National d'Histoire Naturelle, 1992, $104 \mathrm{p}$.

KAMASE L.M. Distribuição das Estacas de madeira no sítio arqueológico de Santa Elina (M.T.). Maîtrise de Géographie - FFLCA USP, 1999, 67 p., 27 fig.

KEROUALIN F. de. Contribution à l'étude d'un site d'art rupestre : Morro da Falha (Mato Grosso), Brésil. Maîtrise de Préhistoire, Paris I Sorbonne, 1988, 144 p., 45 ph.

LORENZATO Elidia. Arte rupestre Cidade de Pedra TGI UFMT Rondonopolis, 2005.

MONTEIRO L. C. Abrigos e aldeias: análise dos contextos tecnológicos das ocupações de ceramistas na Cidade de Pedra, Rondonópolis, Mato Grosso. Dissertação de Mestrado 22/02/06, MAE-USP, 2006. 
PACHECO, M. L. A. F. Zooarqueologia dos sítios arqueológicos Maracaju 1, MS e Santa Elina, MT. Dissertação de Mestrado MAE-USP, 2009.

Internet para acessar o site Mato Grosso

www.diplomatie.gouv.fr

coopération et développement

coopération universitaire et de recherche

carnets d'Archéologie 